\title{
Classroom based cognitive behavioural therapy in reducing symptoms of depression in high risk adolescents: pragmatic cluster randomised controlled trial
}

\author{
(c) $\begin{gathered}\text { (1) (8) } \\ \text { ay }\end{gathered}$
}

Paul Stallard professor of child and family mental health ${ }^{1}$, Kapil Sayal clinical associate professor and reader in child and adolescent psychiatry ${ }^{2}$, Rhiannon Phillips research fellow/clinical trial manager ${ }^{1}$, John A Taylor research officer ${ }^{2}$, Melissa Spears NIHR research methods training fellow ${ }^{3}$, Rob Anderson associate professor of health economics and evaluation ${ }^{4}$, Ricardo Araya professor of psychiatry ${ }^{5}$, Glyn Lewis professor of psychiatric epidemiology ${ }^{5}$, Abigail Millings research officer ${ }^{1}$, Alan A Montgomery reader in health sciences research ${ }^{3}$

${ }^{1}$ Child and Adolescent Mental Health Research Group, Department of Health, University of Bath, Bath BA2 7AY, UK; ${ }^{2}$ Section of Developmental Psychiatry and Institute of Mental Health, University of Nottingham, UK; ${ }^{3}$ School of Social and Community Medicine, University of Bristol, UK; ${ }^{4}$ University of Exeter Medical School, University of Exeter, UK; ${ }^{5}$ Academic Unit of Psychiatry, Bristol University

\begin{abstract}
Objective To compare the effectiveness of classroom based cognitive behavioural therapy with attention control and usual school provision for adolescents at high risk of depression.

Design Three arm parallel cluster randomised controlled trial.

Setting Eight UK secondary schools.

Participants Adolescents $(n=5030)$ aged $12-16$ years in school year groups 8-11. Year groups were randomly assigned on a 1:1:1 ratio to cognitive behavioural therapy, attention control, or usual school provision. Allocation was balanced by school, year, number of students and classes, frequency of lessons, and timetabling. Participants were not blinded to treatment allocation.

Interventions Cognitive behavioural therapy, attention control, and usual school provision provided in classes to all eligible participants.

Main outcome measures Outcomes were collected by self completed questionnaire administered by researchers. The primary outcome was symptoms of depression assessed at 12 months by the short mood and feelings questionnaire among those identified at baseline as being at high risk of depression. Secondary outcomes included negative thinking, self worth, and anxiety. Analyses were undertaken on an intention to treat basis and accounted for the clustered nature of the design.

Results 1064 (21.2\%) adolescents were identified at high risk of depression: 392 in the classroom based cognitive behavioural therapy arm, 374 in the attention control arm, and 298 in the usual school
\end{abstract}

provision arm. At 12 months adjusted mean scores on the short mood and feelings questionnaire did not differ for cognitive behavioural therapy versus attention control $(-0.63,95 \%$ confidence interval -1.85 to 0.58 , $\mathrm{P}=0.41$ ) or for cognitive behavioural therapy versus usual school provision $(0.97,-0.20$ to $2.15, P=0.12)$.

Conclusion In adolescents with depressive symptoms, outcomes were similar for attention control, usual school provision, and cognitive behavioural therapy. Classroom based cognitive behavioural therapy programmes may result in increased self awareness and reporting of depressive symptoms but should not be undertaken without further evaluation and research.

Trial registration Current Controlled Trials ISRCTN19083628.

\section{Introduction}

Depression in adolescents is an important mental health disorder. By age 19 up to $20 \%$ of adolescents will have experienced at least one clinically important depressive episode, which can affect developmental trajectories, interfere with educational attainment, and increase the risk of attempted and completed suicide as well as major depressive disorder in adulthood. ${ }^{1-4}$ Although depressive episodes may be persistent in adolescents, with episodes lasting a median $1-2$ years, ${ }^{56}$ depression is poorly recognised and comparatively few people receive specialist treatment. ${ }^{7-10}$ Initial recovery with or without treatment is often good, but recurrence is common, with up to $75 \%$ of people 
experiencing another episode within five years. ${ }^{11}{ }^{12}$ The risk of poor outcomes is not contingent on meeting criteria for a depressive disorder as even subthreshold depressive symptoms in adolescence carry a considerable risk for later depression and suicidal behaviours. ${ }^{13}$ This highlights the importance of preventive measures for adolescents at high risk involving improved access to interventions in community settings such as schools.

The burden of depression and the limited reach and long term effectiveness of traditional treatment has led to increased interest in approaches to prevent depression. ${ }^{714}$ The goals of prevention programmes are to reduce current levels of symptomatology and to maximise future coping and well being. Prevention programmes can be widely provided to all of an identified population (universal approaches) regardless of risk status, or targeted (selective or indicated approaches) towards those at increased risk of developing problems or displaying subclinical symptoms. Universal approaches can have good population coverage and are inclusive and non-stigmatising, whereas selective and indicated programmes typically produce greater treatment effects and are a more focused use of available resources. ${ }^{14}$ For children, schools provide a convenient and accessible location for delivering depression prevention programmes. Several school based trials have been reported but although universal and targeted programmes can be efficacious, the results were mixed and the effects often modest. ${ }^{15}{ }^{16}$ Many studies have been small efficacy trials and therefore it is unclear whether meaningful treatment effects could be achieved if widely implemented under everyday conditions. Comparisons with attention control groups are also lacking and it is unclear whether reported treatment effects are due to the intervention itself or to the non-specific placebo effect, which is particularly important in studies on depression. ${ }^{17}$ Before the widespread implementation of school based depression prevention programmes can be supported, effectiveness needs to be assessed under real life conditions using appropriate control groups.

We carried out a pragmatic evaluation of the effectiveness of a classroom based cognitive behavioural therapy programme (the resourceful adolescent programme ${ }^{18}$ ) when implemented in UK schools.

\section{Methods}

We undertook a three arm parallel cluster randomised controlled trial, with school year group as the unit of allocation and individual participants as the unit of analysis. ${ }^{19}$ Randomisation by school year rather than by individual class minimised the potential for contamination between trial arms. Eligible schools were non-denominational mixed sex secondary schools in five local education authorities incorporating urban and rural sites in the East Midlands and south west of England. All adolescents in years 8-11 (ages 12-16 years) in the participating schools were eligible unless they were not attending school (for example, through long term sickness, exclusion, or alternative education) or did not participate in personal, social, and health education (PSHE) lessons for religious or other reasons.

Participation required consent from the head teachers and parent and signed assent from the adolescents. Although the primary aim was to determine the effectiveness of the programme among those adolescents identified at baseline as being at high risk of depression, the allocated intervention was delivered to all participants in each year group (universal delivery). Classification of risk was based on increased levels of depressive symptoms and continuity of those symptoms over time. We classified participants as being at high risk of depression if they scored 5 or more on the short mood and feelings questionnaire ${ }^{20}$ on two separate occasions about two weeks apart. ${ }^{19}$

\section{Randomisation}

Once the schools had been recruited we allocated year groups on a 1:1:1 ratio. We balanced the trial arms for key characteristics by calculating an imbalance statistic for a large random sample of possible allocation sequences. ${ }^{21}$ Variables used for balancing were school, year groups, number of students, number of classes, and frequency and timetabling of personal, social, and health education lessons. A statistician with no other involvement in the study randomly selected one sequence from a subset with the most desirable balance properties.

\section{Interventions}

Interventions were delivered in the academic year September 2009 to July 2010 during personal, social, and health education lessons.

\section{Classroom based cognitive behavioural therapy (the resourceful adolescent programme)}

The resourceful adolescent programme is a universal depression prevention programme that has been shown to be effective in Australia and New Zealand. ${ }^{182}$ The programme was developed to be delivered in schools and provided to whole classes. The feasibility and viability of delivering the programme in UK schools has been established. ${ }^{23}$

The resourceful adolescent programme, based on the principles of cognitive behavioural therapy, develops skills such as emotion-regulation capacities, coping mechanisms, and thinking styles, which are reported to protect against the development of depression. ${ }^{10}$ The programme consists of nine modules and two booster sessions, each lasting about 50-60 minutes. The modules can be flexibly delivered to fit within the school timetable. Two trained facilitators led each session working alongside the class teacher. The facilitators had at least an undergraduate university degree in a relevant discipline, appropriate professional backgrounds, or experience of working with children or young people. To avoid contamination the facilitators in the resourceful adolescent programme and attention control groups received separate initial training and ongoing supervision. Facilitators were blind to the risk status of the pupils.

Treatment fidelity was assessed by independent observation of $5 \%$ of the resourceful adolescent programme sessions.

Facilitators rated the content of each of these and the attention control sessions they were involved with on a 5 point scale.

\section{Attention control}

The attention control intervention concerned similar time and contact as the classroom based cognitive behavioural therapy intervention. The class teacher led and delivered the usual curriculum for personal, social, and health education. Two facilitators not involved in delivering the cognitive behavioural therapy programme assisted with lesson delivery and engagement of the pupils. Delivery of the attention control intervention was flexible to fit with the existing personal, social, and health education programmes.

\section{Usual school provision}

Students in the usual school provision arm participated in the personal, social, and health education sessions provided by the 
school. The sessions were provided by the teacher with no external input from the research team.

\section{Outcome measures}

Outcomes were collected during class time by self completed questionnaires administered by researchers blind to arm allocation at screening, baseline (two weeks later), and six and 12 months. ${ }^{19}$ As described in the trial protocol, ${ }^{19}$ the primary outcome was symptoms of low mood as determined by the short mood and feelings questionnaire ${ }^{20}$ at 12 months after baseline. Secondary outcome measures assessed negative thinking (personal failure subscale of the children's automatic thoughts scale) $)^{24}$; self worth and acceptance ${ }^{25}$; anxiety (revised child anxiety and depression scale $)^{26}$; feeling respected, valued and included in school (psychological sense of school membership) ${ }^{27}$; relationships with peers; extent of bullying by others, and whether the student had been the victim of bullying; alcohol consumption; cannabis use; use of other drugs; and thoughts of self harm, and whether self harm had been experienced. An economic analysis was undertaken but the results are not reported here.

\section{Statistical analysis}

We powered the study to detect a difference of two points in mean short mood and feelings questionnaire scores between classroom based cognitive behavioural therapy and each of the control arms. This is consistent with effect sizes of universally delivered psychological interventions reported in the Cochrane review. ${ }^{28}$ A pilot site provided estimates of intracluster correlation coefficient $(0.025)$, mean year group size $(n=203)$, consent rate (84\%), and standard deviation of scores on the short mood and feelings questionnaire in the target population (score 4.9). Based on $80 \%$ consent, $80 \%$ retention, and $20 \%$ of adolescents being classified as at high risk, we anticipated a mean cluster size for analysis of 26 high risk participants, requiring a total of 22 year groups to detect a difference of two points with $80 \%$ power and $2.7 \%$ Dunnett corrected two sided $\alpha$. The Dunnett correction for multiple comparisons can be applied in studies where there is more than one intervention arm and each is compared with the control arm, in this case maintaining overall two sided $\alpha$ at $5 \%$.

We used descriptive statistics to assess balance between the trial arms at baseline. The primary outcome was assessed by intention to treat without imputation. To take appropriate account of the hierarchical nature of the data, we used multivariable mixed effects regression to compare mean scores on the short mood and feelings questionnaire at 12 months for classroom based cognitive behavioural therapy compared with each of attention control and usual school provision groups, with adjustment for baseline scores and randomisation variables. In a secondary analysis we further adjusted for variables that were imbalanced between the trial arms at baseline. We repeated these analyses for secondary outcomes and undertook several further analyses for the short mood and feelings questionnaire. To investigate convergence and divergence between trial arms over time we used repeated measures mixed effects regression models. We carried out preplanned subgroup analyses using interaction terms in the regression models between randomised arm and the baseline variables: symptom severity (short mood and feelings questionnaire score 5-10, $\geq 11$ ), self harm (no, yes ), alcohol or drug misuse (no, yes), year group (8-11), and family affluence. ${ }^{19}$

We conducted sensitivity analyses to assess the potential effect of missing data using multiple imputation chained equation methods, ${ }^{29}$ with the imputation model including all variables associated with missingness of the primary outcome at 12 months. We investigated variance at class and school level by including these in the multilevel models. Neither of these sensitivity analyses made any material difference to the primary results and therefore the data presented are those from two level (individual and year group) models based on observed data only. Finally, we investigated the effect of attendance at allocated lessons by estimating the compiler average causal effect using instrumental variable regression, ${ }^{30}$ weighted with inverse probability weights constructed from baseline short mood and feelings questionnaire scores, randomised group, and "adherence" (defined as attendance at $60 \%$ or more of sessions).

\section{Results}

Of 66 schools invited to take part in the study, eight agreed to participate. Seven schools had all four year groups (year groups 8-11) the other, a new school, had three (year groups 8-10). The number of eligible pupils per school (ages 12-16 years) ranged from 396 to 1056, with the number of classes per year group ranging from four to 12 . The eight schools were representative of schools in the United Kingdom for ethnicity, deprivation (eligibility for free school meals), pupil absence rates, and academic ability (examination results and proportion of children with identified special educational needs).

Three year groups were excluded as they did not have timetabled lessons in personal, social, and health education, and the remaining 28 year groups were randomly allocated (figure $\downarrow$ ). Of the 5503 eligible participants, 5030 (91.4\%) consented to participate in the study, of whom 1064 (21.2\%) were defined at baseline as being at high risk of depression.

The proportion of high risk participants providing baseline data was lower in the usual school provision arm $(n=298,18.6 \%)$ than in the other two arms (22.4\%). More year 8 and fewer year 10 participants were in the usual school provision group than in the other two groups. Consequently the mean age was slightly lower in the usual school provision arm, but otherwise the arms were well balanced at baseline (table $1 \Downarrow$ ).

Participants in the classroom based cognitive behavioural therapy arm attended a median of $88 \%$ of sessions (interquartile range $67-100 \%)$ compared with $89 \%(78-100 \%)$ in the attention control arm. Eighty per cent $(n=252 / 316)$ and $93 \%(n=321 / 346)$ of participants in the classroom based cognitive behavioural therapy and attention control arms, respectively, attended at least $60 \%$ of sessions. Details were not collected of attendance at personal, social, and health education lessons in the usual school provision arm.

Of the 36 class based cognitive behavioural therapy sessions observed to assess intervention fidelity, 31 covered all the specified core tasks, with at least $75 \%$ of core tasks being covered in the remaining five. Compared with attention control, there was strong evidence that the cognitive behavioural therapy programme focused more on self esteem, emotional awareness, and positive thinking, with the attention control sessions being rated higher on topics traditionally covered in personal, social, and health education lessons - that is, sex education, ethical issues, diversity, religion, and citizenship (data not shown).

Primary outcome data at 12 months were collected from 846 (79.5\%) high risk participants, with $76 \%(n=296 / 392)$ in the classroom based cognitive behavioural therapy arm compared with $81 \%(n=242 / 298)$ and $82 \%(n=308 / 374)$ in the usual school provision and attention control arms, respectively. There was no evidence of any difference in adjusted mean scores on the short mood and feelings questionnaire at 12 months for classroom based cognitive behavioural therapy compared with 
usual school provision or attention control (table $2 \Downarrow$ ). The $95 \%$ confidence intervals for the adjusted treatment differences all but excluded the predefined clinically important difference of 2 points, although it was not possible to rule out a potential small clinical harm of classroom based cognitive behavioural therapy compared with usual school provision.

When the short mood and feelings questionnaire was analysed as a binary outcome, with a score of less than 5 representing response, there was some evidence of a greater response in the classroom based cognitive behavioural therapy arm compared with attention control arm $(36 \% v 29 \%$, tables $3 \Downarrow$ and $4 \Downarrow)$. Analysis of other secondary outcomes suggested no differences between the treatment arms, with the exception of participants in the classroom based cognitive behavioural therapy arm having a worse score on the children's automatic thoughts scale at follow-up compared with participants in the usual school provision arm (table 3 ).

There was no evidence that the between group differences in mean scores on the short mood and feelings questionnaire changed over time (classroom based cognitive behavioural therapy versus attention control interaction coefficient -0.17 , $95 \%$ confidence interval -1.40 to $1.06, \mathrm{P}=0.79$; classroom based cognitive behavioural therapy versus usual school provision interaction coefficient $0.72,-0.59$ to $2.03, \mathrm{P}=0.28$ ). The instrumental variable analysis did not alter the conclusions of the primary analysis for classroom based cognitive behavioural therapy compared with attention control (adjusted difference $-0.82,95 \%$ confidence interval -1.79 to $0.14, \mathrm{P}=0.09$ ). However, for classroom based cognitive behavioural therapy compared with usual school provision, the evidence was stronger for a higher mean short mood and feelings questionnaire score at 12 months in the cognitive behavioural therapy group-that is, more symptoms of low mood (adjusted difference 1.43, 1.22 to $1.64, \mathrm{P}<0.001)$.

There was no evidence from the subgroup analyses that the effect of classroom based cognitive behavioural therapy was modified by any of the predefined baseline variables that were examined (table $5 \Downarrow$ ).

\section{Discussion}

Despite high levels of fidelity and adherence to classroom based cognitive behavioural therapy, we found no evidence that the intervention reduced depressive symptoms in adolescents at high risk of depression when implemented under diverse everyday conditions. In this non-referred sample from the community, adolescents with high levels of depressive symptoms showed modest improvements over time that may reflect regression to the mean regardless of whether they received a focused classroom based cognitive behavioural therapy intervention. Despite this, at the 12 month follow-up around two thirds of high risk participants continued to be at risk of depression.

This is the first large scale pragmatic randomised trial to compare a focused classroom based cognitive behavioural therapy programme with usual school provision and an attention control group on symptoms of low mood in adolescents. The cognitive behavioural therapy intervention specifically targeted factors reported to protect against the development of depression - that is, thinking styles, emotional recognition, and regulation and coping skills. ${ }^{10}$ However, we observed that this intervention may have a potentially harmful effect compared with usual school provision. The higher rates of depressive symptoms in the intervention group at 12 months may indicate a detrimental effect reflecting limited improvement in mood over time. While the possibility of a harmful effect needs to be acknowledged, higher rates of symptoms may reflect greater self recognition and acknowledgement of existing symptoms of depression and negative thinking styles. Unfortunately our data do not extend beyond 12 months and so the longer term effects of the interventions are not known. None the less, in the short term our results suggest that, compared with no intervention, classroom based cognitive behavioural therapy targeting symptoms of depression was associated with increased levels of depressive symptoms. The possibility of worse outcomes after school based intervention programmes has also been found for other mental health disorders such as attention deficit hyperactivity disorder, and an improved understanding of the mechanisms underlying possible adverse outcomes merits further investigation. ${ }^{31}$

\section{Strengths of the study}

Systematic reviews of programmes designed to reduce symptoms of depression in adolescents have noted considerable variability in results but remain supportive of prevention and early intervention approaches delivered in schools. ${ }^{15}{ }^{16}$ Important methodological shortfalls, limited follow-up, and absence of attention control or placebo comparisons have been noted as important omissions. Our study has addressed these issues and has several strengths. We attempted to maximise the effectiveness of the intervention by using a cognitive behavioural therapy programme that has previously proved effective in schools. ${ }^{1822}$ The feasibility of integrating the programme within secondary schools and acceptability to students and teachers was established through a pilot study. ${ }^{23}$ Programme delivery was provided by trained and supervised graduates who tend to be more effective than trained teaching staff at delivering depression prevention programmes. ${ }^{16}$ Participants achieved a sufficient dosage of the cognitive behavioural therapy intervention, programme fidelity was good, recruitment and retention were high, and the study had sufficient power to detect the a priori hypothesised clinically significant between group differences. Despite our attempts we found no evidence to suggest that a focused classroom based cognitive behavioural therapy programme designed to reduce symptoms of depression in high risk adolescents was effective and indeed could result in increased reporting of symptoms of low mood.

\section{Depression prevention in secondary schools}

Our findings suggest a more cautious approach is required to the implementation of depression prevention programmes in secondary schools. In terms of context, although secondary schools provide a convenient focus for mental health interventions, the suitability of this setting for depression focused interventions cannot be assumed. The success and sustainability of mental health interventions within this setting will be determined by several factors other than programme efficacy. These include compatibility with organisational objectives, perceived relevance, programme flexibility, and fit within existing structures. ${ }^{14}$ Secondary schools are organisationally complex and although the importance of developing social and emotional awareness is increasingly being recognised, the primary objective of schools is to develop academic skills. We addressed this issue by using a dedicated team of trained graduates to deliver the intervention, but the absence of a positive effect suggests that this is not a sustainable or viable option. Training school staff in mental health programmes provides an alternative model, although school staff tend to be less effective than trained graduates or health 
professionals, with a recent implementation trial of a teacher led programme failing to find positive effects. ${ }^{16} 32$

In terms of implementation, although the schools were supportive we regularly experienced practical difficulties with timetabling. Scheduling of the cognitive behavioural therapy sessions was a lower priority for schools that had many statutory teaching requirements. Delivery therefore required flexibility and we were often under pressure to reduce the length of the programme. Thus while secondary schools offer a natural location for accessing large numbers of adolescents, implementing and sustaining depression programmes within this context is practically challenging and poses many problems for maintaining the fidelity and potency of efficacious programmes.

\section{Limitations of the study}

Our study had several limitations. The cognitive behavioural therapy programme we used was developed for adolescents aged 12-15 years so the inclusion of 16 year olds could have reduced the effects. However, our analysis failed to find any specific age effects and there was no evidence that one year group benefited more than others. We also relied on self report ratings of depressive symptoms and did not undertake any diagnostic interviews. It is therefore possible that there were important changes in the diagnostic status of those adolescents who were more severely affected (clinically depressed) that we did not capture. Finally, our approach of delivering the intervention to all children while targeting those at high risk of depression may have compromised the potency of the intervention. Although universal approaches are practically easier to implement those with more symptoms may have found it harder to fully engage in a programme dominated by peers with fewer symptoms. ${ }^{14} 15$

\section{Interpretation and implications}

In addition to the issues already highlighted there are other possible explanations for our findings that would warrant further investigation. Firstly, universal prevention programmes tend to produce more modest treatment effects than selective or indicated programmes. The treatment effects reported in smaller universal studies may therefore become further diluted when programmes are widely implemented under more diverse conditions. Secondly, to engage with a group of predominantly healthy individuals, universal prevention programmes tend to teach general skills designed to maximise coping and well being. While these skills may also help to reduce current levels of symptoms, universal programmes may not be sufficiently focused on the specific problems of individual students to help those who are more symptomatic. Thirdly, although the students completed questionnaires assessing mood, all students subsequently participated in the programme and there was no active selection process. This is an inherent aspect of universal programmes and may have resulted in students not perceiving themselves as having symptoms and therefore not recognising the personal relevance of the programme. Fourthly, although cognitive behavioural therapy programmes tend to cover many of the skills reported to protect against the development of low mood, not all cognitive behavioural therapy based programmes are effective. ${ }^{16}$ The manner in which programmes are delivered may be important and unless sessions are active and interesting and led by facilitators who are enthusiastic, confident, and knowledgeable, students may fail to engage with the programme.

\section{Conclusions}

Classroom based prevention programmes to reduce symptoms of depression in adolescents are an appealing concept in terms of their potential convenience and reach. However, our study indicates that depression programmes delivered in schools may not be effective and indeed may increase reporting of symptoms. At present our data suggest that the widespread roll out of classroom based adolescent depression prevention programmes should not be pursued without further research and evaluation.

We thank the schools and students who participated in this project, the facilitators who helped with intervention delivery, the East Midlands Hub of the NIHR Mental Health Research Network for their administrative and research support, the support and guidance of the trial steering committee and data monoitoring ethic committee, and in particular their respective chairs, Laurence Moore and David Gunnell.

Contributors: PS, AAM, KS, RA, RA, and GL conceived and designed the study. RP managed the trial and with JAT and AM supervised data collection. PS and KS organised the conduct of the study and led the trial teams in the south west and East Midlands. AAM and MS undertook the statistical analysis. All authors had access to all study data and participated in interpretation of the findings, contributed core ideas and were involved in critically revising the paper for important intellectual content. All authors read and approved the final manuscript. PS was principal investigator and will act as guarantor for the paper.

Funding: This study was funded by the National Institute of Health Research Health Technology Assessment (06/37/04). The views and opinions expressed therein are those of the authors and do not necessarily reflect those of the HTA programme, NIHR, NHS or the Department of Health. The sponsor of the study had no role in study design, data collection, data analysis, interpretation of data, or writing of the report. The corresponding author had full access to all the data in the study and had final responsibility for the decision to submit for publication.

Competing interests: All authors have completed the ICMJE uniform disclosure form at www.icmje.org/coi_disclosure.pdf (available on request from the corresponding author) and declare: this study was funded by the National Institute of Health Research Health Technology Assessment; no financial relationships with any organisations that might have an interest in the submitted work in the previous three years; and no other relationships or activities that could appear to have influenced the submitted work.

Ethical approval: This study was approved by the University of Bath School for Health Ethics Committee.

Data sharing: No additional data available.

1 Birmaher B, Ryan ND, Williamson DE, Brent DA, Kaufman J, Dahl RE, et al. Childhood and adolescent depression: a review of the past 10 years. Part 1. J Am Acad Child Adolesc Psychiatry 1996;35:1427-39.

2 Lewinsohn PM, Rohde P, Seely JR. Major depressive disorder in older adolesence: prevalence, risk factors and clincial implications. Clin Psychol Rev 1998;18:765-94.

3 Harrington R, Fudge H, Rutter M, Pickles A, Hill J. Adult outcomes of child and adolescent depression, part1: psychiatric status. Arch Gen Psychiatry 1990;47:465-73.

4 Vernberg EM. Psychological adjustment and experiences with peers during early adolescence - reciprocal, incidental, or unidirectional relationships. J Abnorm Child Psychol 1990;18:187-98.

5 Gledhill J, Garralda ME. The short-term outcome of depressive disorder in adolescents attending primary care: a cohort study. Soc Psychiatry Psychiatr Epidemiol 2011;46:993-1002.

6 Dunn V, Goodyer IM. Longitudinal investigation into childhood- and adolescence-onset depression: psychiatric outcome in early adulthood. Br J Psychiatry 2006;188:216-22.

7 Kieling C, Baker-Henningham H, Belfer M, Conti G, Ertern I, Omigbodun O, et al. Child and adolescent mental health worldwide: evidence for action. Lancet 2011;378:1515-25.

8 Logan DE, King CA. Parental identification of depression and mental health service use among depressed adolescents. J Am Acad Child Adolesc Psychiatry 2002;41:296-304.

9 Moor S, Maguire A, McQueen H, Wells JE, Elton R, Wrate R, et al. Improving the recognition of depression in adolescence: can we teach the teachers? J Adolesc 2007;30:81-95.

10 Thapar A, Collishaw S, Pine DS, Thapar AK. Depression in adolescence. Lancet 2012;379:1056-67.

11 Lewinsohn PM, Rohde P, Seeley JR, Klein DB, Gotlib IH. Natural course of adolescent major depressive disorders in a community sample: predictors or recurrence in young adults. Am J Psychiatry 2000;157:1548-91. 


\section{What is already known on this topic}

Evidence to date indicates that classroom based psychological programmes can be effective in preventing depression in adolescents Findings are, however, mixed and many studies in this area have methodological shortfalls

Evaluations under real world conditions comparing interventions with appropriate control groups, including an attention control, are lacking

\section{What this study adds}

A classroom based cognitive behavioural therapy (CBT) programme was not effective in reducing symptoms of depression in high risk adolescents compared with usual school provision and attention control

The potential harms of classroom based CBT for adolescents at high risk of depression need to be considered

The widespread use of school based depression prevention programmes for adolescents should not be pursued without further research and evaluation

12 Kennard BD, Emslie GJ, Mayes TL, Hughes JL. Relapse and recurrence in paediatric depression. Child Adolesc Psychiatr Clin N Am 2006;15:1057-79.

13 Fergusson DM, Horwood LJ, Ridder EM, Beautrais AL. Subthreshold depression in adolescence and mental health outcomes in adulthood. Arch Gen Psychiatry 2005;62:66-72.

14 Giesen F, Searle A, Sawyer M. Identifying and implementing prevention programmes for childhood mental health problems. J Paediatr Child Health 2007;43:785-9.

15 Merry SN, Hetrick SE, Cox GR, Brudevold-Iversen T, Bir JJ, McDowell H. Psychological and educational interventions for preventing depression in children and adolescents. Cochrane Database Syst Rev 2100;(12):CD003380.

16 Calear AL, Christensen H. Systematic review of school-based prevention and early intervention programs for depression. J Adolesc 2010;33:429-38.

17 Shapiro A, Shapiro E. The powerful placebo; from ancient priest to modern physician. John Hopkins University Press, 1997.

18 Shochet I, Ham D. Universal school-based approaches to preventing adolescent depression: past findings and future directions of the Resourceful Adolescent Program. Int J Ment Health Prom 2004;6:17-25.

19 Stallard P, Montgomery AA, Araya R, Anderson R, Lewis G, Sayal K, et al. Protocol for a randomised controlled trial of a school based cognitive behaviour therapy (CBT) intervention to prevent depression in high risk adolescents (PROMISE). Trials 2010;11:114

20 Angold A, Costello E, Messer S, Pickles A, Winder F, Silver D. Development of a short questionnaire for use in epidemiological studies of depression in children and adolescents. Int J Methods Psychiatr Res 1995;5:237-49.

21 Raab GM, Butcher I. Balance in cluster randomized trials. Stat Med 2001;20:351-65.

22 Merry S, McDowell H, Wild CJ, Bir J, Cunliffe R. A randomized placebo-controlled trial of a school-based depression prevention program. J Am Acad Child Adolesc Psychiatry 2004:43:538-47.

23 Stallard P, Buck R. Preventing depression and promoting resilience through CBT-based school interventions: a feasibility study of a school based depression prevention programme (PROMISE). Br J Psychiatry 2012;201:s18-23.

24 Schniering CA, Rapee RM. Development and validation of a measure of children's automatic thoughts: the children's automatic thoughts scale. Behav Res Ther 2002:40:1091-109.
25 Rosenberg M. Society and the adolescent self-image. Princeton University Press, 1965. 26 Chorpita BF, Yim L, Moffitt C, Umemoto LA, Francis SE. Assessment of symptoms of DSM-IV anxiety and depression in children: a revised child anxiety and depression scale. Behav Res Ther 2000;38:835-55.

27 Goodenow C. The psychological sense of school membership among adolescents: scale developments and educational correlates. Psychol Sch 1993;30:79-90.

28 Merry SN, McDowell HH, Hetrick SE, Bir JJ, Muller N. Psychological and/or educational interventions for the prevention of depression in children and adolescents. Cochrane Database Syst Rev 2004;(2):CD003380.

29 Sterne JA, White IR, Carlin JB, Spratt M, Royston P, Kenward MG, et al. Multiple imputation for missing data in epidemiological and clinical research: potential and pitfalls. $B M J$ 2009;338:b2393.

30 Dunn G, Maracy M, Tomenson B. Estimating treatment effects from randomized clinical trials with noncompliance and loss to follow-up: the role of instrumental variable methods. Sta Methods Med Res 2005;14:369-95.

31 Sayal K, Owen V, White K, Merrell C, Tymms P, Taylor E. The impact of early school-based screening and intervention programs for ADHD on children's outcomes and access to services-follow-up of a school-based trial at age 10 years. Arch Pediatr Adolesc Med 2010;164,5:462-9.

32 Sawyer MG, Pfeiffer S, Spence SH, Bond L, Graetz B, Kay D, et al. School-based prevention of depression: a randomised controlled trial of the beyond blue initiative. $J$ Child Psychol Psychiatry 2006;74,3:401-15.

\section{Accepted: 28 August 2012}

\section{Cite this as: BMJ 2012;345:e6058}

This is an open-access article distributed under the terms of the Creative Commons Attribution Non-commercial License, which permits use, distribution, and reproduction in any medium, provided the original work is properly cited, the use is non commercial and is otherwise in compliance with the license. See: http://creativecommons.org/licenses/bync/2.0/ and http://creativecommons.org/licenses/by-nc/2.0/legalcode. 


\section{Tables}

Table 1 | Characteristics of participants at baseline for all adolescents and for those at high risk of depression, by trial arm. Values are numbers (percentages) unless stated otherwise

\begin{tabular}{|c|c|c|c|c|c|c|}
\hline \multirow[b]{2}{*}{ Characteristics } & \multicolumn{2}{|c|}{ Usual school provision } & \multicolumn{2}{|c|}{ Classroom based CBT } & \multicolumn{2}{|c|}{ Attention control } \\
\hline & All $(n=1604)$ & High risk $(n=298)$ & All $(n=1753)$ & $\begin{array}{c}\text { High risk } \\
(\mathrm{n}=392)\end{array}$ & All $(n=1673)$ & High risk $(n=374)$ \\
\hline Male & $834(52)$ & $101(34)$ & $880(50)$ & $132(34)$ & $849(51)$ & $135(36)$ \\
\hline Female & $770(48)$ & $197(66)$ & $873(50)$ & $260(66)$ & $824(49)$ & $239(64)$ \\
\hline \multicolumn{7}{|l|}{ Ethnicity: } \\
\hline White & $1275(86)$ & $246(87)$ & $1372(87)$ & $314(88)$ & $1271(84)$ & $286(82)$ \\
\hline Non-white & $205(14)$ & $38(13)$ & $210(13)$ & $44(12)$ & $250(16)$ & $64(18)$ \\
\hline \multicolumn{7}{|l|}{ Parental status: } \\
\hline Both parents & $981(67)$ & $149(53)$ & $972(62)$ & $186(52)$ & $1019(67)$ & $189(54)$ \\
\hline Parent and partner & $193(13)$ & $46(16)$ & $224(14)$ & $64(18)$ & $189(12)$ & $69(20)$ \\
\hline Single parent & $262(18)$ & $73(26)$ & $343(22)$ & $96(27)$ & $283(19)$ & $87(25)$ \\
\hline Other & $30(2)$ & $11(4)$ & $23(1)$ & $12(3)$ & $29(2)$ & $7(2)$ \\
\hline \multicolumn{7}{|l|}{ Year group: } \\
\hline 8 & $569(35)$ & $112(38)$ & $470(27)$ & $66(17)$ & $374(22)$ & $79(21)$ \\
\hline 9 & $469(29)$ & $89(30)$ & $384(22)$ & $81(21)$ & $541(32)$ & $102(27)$ \\
\hline 10 & $179(11)$ & $17(6)$ & $583(33)$ & $153(39)$ & $562(34)$ & $144(39)$ \\
\hline 11 & $387(24)$ & $80(27)$ & $316(18)$ & $92(23)$ & $196(12)$ & $49(13)$ \\
\hline \multicolumn{7}{|l|}{$\begin{array}{l}\text { Thoughts about self } \\
\text { harm: }\end{array}$} \\
\hline Never & $1203(83)$ & $130(47)$ & $1239(80)$ & $160(45)$ & $1194(79)$ & $160(46)$ \\
\hline Once or twice & $198(14)$ & $102(37)$ & $244(16)$ & $144(40)$ & $238(16)$ & $132(38)$ \\
\hline$\geq 3$ times & $56(4)$ & $45(16)$ & $71(5)$ & $53(15)$ & $73(5)$ & $57(16)$ \\
\hline \multicolumn{7}{|l|}{ Self harm behaviour: } \\
\hline Never & $1343(92)$ & $201(72)$ & $1391(90)$ & $249(70)$ & $1346(89)$ & $240(69)$ \\
\hline Once or twice & $72(5)$ & $50(18)$ & $112(7)$ & $68(19)$ & $101(7)$ & $62(18)$ \\
\hline$\geq 3$ times & $41(3)$ & $27(10)$ & $50(3)$ & $38(11)$ & $59(4)$ & $47(13)$ \\
\hline \multicolumn{7}{|l|}{ Alcohol consumption: } \\
\hline Never & $518(36)$ & $77(28)$ & $471(30)$ & $82(23)$ & $540(36)$ & $88(25)$ \\
\hline Once or twice & $638(44)$ & $121(44)$ & $753(49)$ & $164(46)$ & $706(47)$ & $162(47)$ \\
\hline$\geq 2-4$ times a month & $246(17)$ & $64(23)$ & $257(17)$ & $81(23)$ & $202(14)$ & $75(22)$ \\
\hline More than once a week & $48(3)$ & $13(5)$ & $71(5)$ & $31(9)$ & $45(3)$ & $22(6)$ \\
\hline \multicolumn{7}{|l|}{ Street drug use: } \\
\hline Never & $1433(99)$ & $268(97)$ & $1502(97)$ & $332(93)$ & $1471(98)$ & $333(95)$ \\
\hline Once or twice & $11(1)$ & $5(2)$ & $39(3)$ & $20(6)$ & $26(2)$ & $15(4)$ \\
\hline 2-4 times a month & $1(0)$ & $1(0)$ & $7(0)$ & $5(1)$ & $1(0)$ & $0(0)$ \\
\hline More than once a week & $2(0)$ & $1(0)$ & $2(0)$ & $0(0)$ & $2(0)$ & $1(0)$ \\
\hline \multicolumn{7}{|l|}{ Cannabis use: } \\
\hline Never & $1351(93)$ & $246(89)$ & $1389(90)$ & $304(85)$ & $1357(90)$ & $288(82)$ \\
\hline Once or twice & $66(5)$ & $15(5)$ & $107(7)$ & $37(10)$ & $109(7)$ & $51(15)$ \\
\hline 2-4 times a month & $18(1)$ & $9(3)$ & $31(2)$ & $8(2)$ & $17(1)$ & $8(2)$ \\
\hline More than once a week & $16(1)$ & $6(2)$ & $22(1)$ & $8(2)$ & $18(1)$ & $4(1)$ \\
\hline Mean (SD) age (years) & $13.9(1.2)$ & $13.9(1.2)$ & $14.1(1.1)$ & $14.4(1.0)$ & $14.0(1.0)$ & $14.1(1.0)$ \\
\hline Mean (SD) SMFQ score & $3.5(4.7)$ & $10.6(4.9)$ & $4.1(4.9)$ & $10.6(4.9)$ & $3.9(4.8)$ & $10.6(4.7)$ \\
\hline Mean (SD) RCADS score & $11.8(9.5)$ & $24.1(10.7)$ & $13.3(10.3)$ & $25.0(10.8)$ & $12.6(10.3)$ & $24.3(11.0)$ \\
\hline Mean (SD) RSE score & $21.4(5.2)$ & $15.9(4.8)$ & $21.0(5.4)$ & $15.5(4.7)$ & $20.9(5.3)$ & $15.4(4.4)$ \\
\hline Mean (SD) CATS score & $4.1(6.7)$ & $12.2(9.3)$ & $4.6(7.1)$ & $12.4(9.2)$ & $4.7(7.1)$ & $13.3(9.0)$ \\
\hline
\end{tabular}


Table 1 (continued)

\begin{tabular}{|c|c|c|c|c|c|}
\hline \multirow[b]{2}{*}{ Characteristics } & Usual school provision & \multicolumn{2}{|c|}{ Classroom based CBT } & \multicolumn{2}{|c|}{ Attention control } \\
\hline & All $(n=1604) \quad$ High risk $(n=298)$ & All $(n=1753)$ & $\begin{array}{l}\text { High risk } \\
(\mathrm{n}=392)\end{array}$ & All $(n=1673)$ & High risk $(n=374)$ \\
\hline
\end{tabular}

$\mathrm{CBT}=$ cognitive behavioural therapy; SMFQ=short mood and feelings questionnaire (range 0-26); RCADS=revised child anxiety and depression scale (range 0-75); RSE= Rosenberg self esteem scale (range 0-30); CATS=children's automatic thoughts scale (range 0-40). 
Table 2| Analysis of primary outcome (short mood and feelings questionnaire at 12 months) for high risk participants, for classroom based cognitive behavioural therapy (CBT) compared with each of usual school provision and attention control personal, social, and health education (PSHE). Values are mean (SD) scores unless stated otherwise

\begin{tabular}{|c|c|c|c|}
\hline Intervention & Baseline & 12 months & $\begin{array}{c}\text { Adjusted difference* }(95 \% \mathrm{Cl}): \text { CBT } v \\
\text { intervention }\end{array}$ \\
\hline Classroom based CBT & $10.64(4.91)$ & $8.22(6.45)(n=296)$ & - \\
\hline Usual school provision & $10.56(4.93)$ & $6.81(5.70)(n=242)$ & $0.97(-0.20$ to 2.15$) \mathrm{P}=0.12$ \\
\hline Attention control PSHE & $10.60(4.67)$ & $8.50(5.88)(n=308)$ & $-0.63(-1.85$ to 0.58$) P=0.41$ \\
\hline
\end{tabular}

Intracluster correlation coefficient for SMFQ at 12 months for high risk participants was $0.012(95 \%$ confidence interval $<0.001$ to 0.039$)$. Confidence intervals and $P$ values are adjusted for multiple comparisons using Dunnett's method.

*Adjusted for number of students, number of classes, frequency of delivery, school, and baseline short mood and feelings questionnaire score. 
Table 3| Analysis of secondary outcomes for high risk participants, for classroom based cognitive behavioural therapy (CBT) compared with each of usual school provision and attention control personal, social, and health education (PSHE). Values are means (standard deviations) scores unless stated otherwise

\begin{tabular}{|c|c|c|c|c|c|c|c|c|}
\hline \multirow[b]{2}{*}{ Variables } & \multicolumn{2}{|c|}{ Usual school provision } & \multirow{2}{*}{$\begin{array}{c}\text { Adjusted } \\
\text { difference* }(95 \% \\
\text { CI) at } 12 \text { months: } \\
\text { CBT } v \text { usual } \\
\text { school provision }\end{array}$} & \multicolumn{2}{|c|}{ Classroom based CBT } & \multirow{2}{*}{$\begin{array}{c}\text { Adjusted } \\
\text { difference }{ }^{\star}(95 \% \\
\text { CI) at } 12 \text { months: } \\
\text { CBT } v \text { attention } \\
\text { control }\end{array}$} & \multicolumn{2}{|c|}{ Attention control PSHE } \\
\hline & Baseline & 12 months & & Baseline & 12 months & & Baseline & 12 months \\
\hline CATS & $12.20(9.28)$ & $8.18(8.68)$ & 1.95 (0.25 to 3.66$)$ & $12.40(9.21)$ & $10.48(10.00)$ & $0.29(-1.48$ to 2.07$)$ & $13.35(8.99)$ & $10.63(9.94)$ \\
\hline RSE & $15.88(4.80)$ & $17.39(5.34)$ & $0.12(-0.81$ to 1.05$)$ & $15.54(4.70)$ & $16.93(5.65)$ & $\begin{array}{c}-0.13(-1.12 \text { to } \\
0.87)\end{array}$ & $15.36(4.38)$ & $16.68(5.25)$ \\
\hline Total RCADS & 24.07 (10.69) & $19.27(11.64)$ & $1.48(-0.64$ to 3.59$)$ & $25.04(10.80)$ & $22.16(12.38)$ & $\begin{array}{c}-0.60(-2.88 \text { to } \\
1.67)\end{array}$ & $24.29(11.01)$ & $22.27(11.74)$ \\
\hline \multicolumn{9}{|l|}{$\begin{array}{l}\text { RCADS } \\
\text { subscales: }\end{array}$} \\
\hline $\begin{array}{l}\text { General } \\
\text { anxiety }\end{array}$ & $5.74(2.87)$ & $4.67(3.05)$ & $0.41(-0.15$ to 0.97$)$ & $5.92(2.84)$ & $5.18(3.12)$ & $\begin{array}{c}-0.24(-0.82 \text { to } \\
0.35)\end{array}$ & $5.77(2.86)$ & $5.40(2.91)$ \\
\hline $\begin{array}{l}\text { Separation } \\
\text { anxiety }\end{array}$ & $2.26(2.19)$ & $1.65(2.17)$ & $0.04(-0.37$ to 0.44$)$ & $2.27(2.26)$ & $1.98(2.34)$ & $\begin{array}{c}-0.18(-0.60 \text { to } \\
0.25)\end{array}$ & $2.35(2.31)$ & $2.09(2.45)$ \\
\hline Social phobia & $6.64(3.24)$ & $5.72(3.31)$ & $0.34(-0.26$ to 0.93$)$ & $6.87(3.33)$ & $6.26(3.57)$ & $0.02(-0.60$ to 0.64$)$ & $6.58(3.22)$ & $6.343 .48)$ \\
\hline Panic & $4.15(3.19)$ & $3.17(3.23)$ & $0.25(-0.31$ to 0.81$)$ & $4.35(3.17)$ & $3.79(3.49)$ & $\begin{array}{c}-0.25(-0.84 \text { to } \\
0.34)\end{array}$ & $4.14(3.16)$ & $3.59(3.18)$ \\
\hline Depression & $5.27(2.83)$ & $4.06(3.26)$ & 0.64 (0.06 to 1.21$)$ & $5.64(2.88)$ & $4.94(3.32)$ & $\begin{array}{c}-0.02(-0.65 \text { to } \\
0.60)\end{array}$ & $5.47(3.10)$ & $4.83(3.19)$ \\
\hline $\begin{array}{l}\text { School } \\
\text { connectedness }\end{array}$ & $26.22(6.19)$ & $26.84(6.94)$ & $0.42(-0.70$ to 1.55$)$ & $25.36(6.20)$ & $26.18(6.80)$ & $0.57(-0.65$ to 1.80$)$ & $25.17(6.04)$ & $25.94(6.64)$ \\
\hline
\end{tabular}

CATS=children's automatic thoughts scale; RSE= RSE=Rosenberg self esteem scale (range 0-30); RCADS=revised child anxiety and depression scale. *Outcome adjusted for number of students, number of classes, frequency of delivery, school, and value of outcome measure at baseline. 
Table 4| Analysis of secondary outcomes for high risk participants, for classroom based cognitive behavioural therapy (CBT) compared with each of usual school provision and attention control personal, social, and health education (PSHE). Values are numbers (percentages) unless stated otherwise

\begin{tabular}{|c|c|c|c|c|c|c|c|c|}
\hline \multirow[b]{2}{*}{ Variables } & \multicolumn{2}{|c|}{ Usual school provision } & \multirow{2}{*}{$\begin{array}{l}\text { Adjusted odds ratio* } \\
\text { (95\% CI) at } 12 \\
\text { months: CBT } v \\
\text { usual school } \\
\text { provision }\end{array}$} & \multicolumn{2}{|c|}{ Classroom based CBT } & \multirow{2}{*}{$\begin{array}{l}\text { Adjusted odds ratio* } \\
(95 \% \text { Cl) at } 12 \\
\text { months: CBT } v \\
\text { attention control } \\
\text { PSHE }\end{array}$} & \multicolumn{2}{|c|}{ Attention control PSHE } \\
\hline & Baseline & 12 months & & Baseline & 12 months & & Baseline & 12 months \\
\hline SMFQ score $<5$ & - & $104 / 242(43.0)$ & $\begin{array}{c}0.85(0.58 \text { to } 1.26) \\
P=0.43\end{array}$ & - & $106 / 296(35.8)$ & $\begin{array}{c}1.64(1.08 \text { to } 2.51) \\
P=0.02\end{array}$ & - & $90 / 308(29.2)$ \\
\hline $\begin{array}{l}\text { Insecure peer } \\
\text { attachment }\end{array}$ & $90(36.73)$ & $79(36.24)$ & $1.00(0.62$ to 1.61$)$ & $141(43.79)$ & $100(40.49)$ & 0.96 (0.59 to 1.56$)$ & $138(42.59)$ & $104(39.85)$ \\
\hline Bullying others & $80(28.88)$ & $41(18.06)$ & $1.29(0.75$ to 2.23$)$ & $96(26.82)$ & $55(20.83)$ & $0.96(0.55$ to 1.69$)$ & $118(33.71)$ & $57(20.50)$ \\
\hline $\begin{array}{l}\text { Thoughts of } \\
\text { deliberate self harm }\end{array}$ & $147(53.07)$ & $90(38.96)$ & 1.06 (0.69 to 1.63$)$ & $197(55.18)$ & $123(46.42)$ & 0.93 (0.59 to 1.46$)$ & $189(54.15)$ & $126(45.00)$ \\
\hline $\begin{array}{l}\text { Deliberate self harm } \\
\text { behaviour }\end{array}$ & $77(27.70)$ & $51(22.17)$ & $1.18(0.71$ to 1.99$)$ & $106(29.86)$ & 77 (29.39) & $1.00(0.56$ to 1.74$)$ & $109(31.23)$ & $71(25.54)$ \\
\hline Alcohol misuse & $77(28.00)$ & $70(30.57)$ & $1.44(0.84$ to 2.47$)$ & $112(31.28)$ & 105 (39.33) & $1.26(0.72$ to 2.20$)$ & $97(27.95)$ & $99(35.61)$ \\
\hline Street drug use & $7(2.55)$ & $13(5.70)$ & $1.22(0.43$ to 3.44$)$ & $25(7.00)$ & $20(7.55)$ & $2.93(1.00$ to 8.61$)$ & $16(4.58)$ & $12(4.30)$ \\
\hline Cannabis use & $30(10.87)$ & $44(19.30)$ & 0.67 (0.36 to 1.27$)$ & $53(14.85)$ & $65(24.34)$ & 1.30 (0.70 to 2.42$)$ & $63(17.95)$ & 55 (19.57) \\
\hline
\end{tabular}

SMFQ=short mood and feelings questionnaire.

*Outcome adjusted for number of students, number of classes, frequency of delivery, school, and value of outcome measure at baseline. 
Table 5 | Subgroup analyses of short mood and feelings questionnaire (SMFQ) score at 12 months for high risk participants, according to baseline subgroups

\begin{tabular}{|c|c|c|c|c|}
\hline \multirow[b]{2}{*}{ Subgroups } & \multicolumn{2}{|c|}{ CBT $v$ usual school provision } & \multicolumn{2}{|c|}{ CBT $v$ attention control PSHE } \\
\hline & Interaction* & $P$ value & Interaction* & $P$ value \\
\hline \multicolumn{5}{|l|}{ SMFQ score: } \\
\hline $5-10$ & Reference & 0.58 & Reference & 0.78 \\
\hline$\geq 11$ & $0.56(-1.44-2.55)$ & & $-0.27(-2.14-1.60)$ & \\
\hline \multicolumn{5}{|l|}{ Self harm: } \\
\hline Yes $v$ no & $0.37(-1.64-2.38)$ & 0.72 & $-0.23(-2.13-1.66)$ & 0.81 \\
\hline \multicolumn{5}{|c|}{ Alcohol, cannabis, or street drug misuse: } \\
\hline Yes $v$ no & $-0.88(-3.09-1.33)$ & 0.44 & $-0.80(-2.81-1.22)$ & 0.44 \\
\hline \multicolumn{5}{|l|}{ Year group: } \\
\hline 8 & Reference & 0.83 & Reference & 0.21 \\
\hline 9 & $-1.64(-6.44-3.16)$ & & $-1.95(-6.41-2.50)$ & \\
\hline 10 & $-2.44(-7.83-2.95)$ & & $-1.83(-5.32-1.66)$ & \\
\hline 11 & $-1.59(-6.64-3.47)$ & & $-5.33(-10.55--0.11)$ & \\
\hline Family affluence scale & $-0.45(-1.11-0.21)$ & 0.18 & $-0.02(-0.68-0.64)$ & 0.95 \\
\hline
\end{tabular}

$\mathrm{CBT}=$ cognitive behavioural therapy; $\mathrm{PSHE}=$ personal, social, and health education.

*Adjusted for number of students, number of classes, frequency of delivery, school, and baseline SMFQ score where applicable. 


\section{Figure}

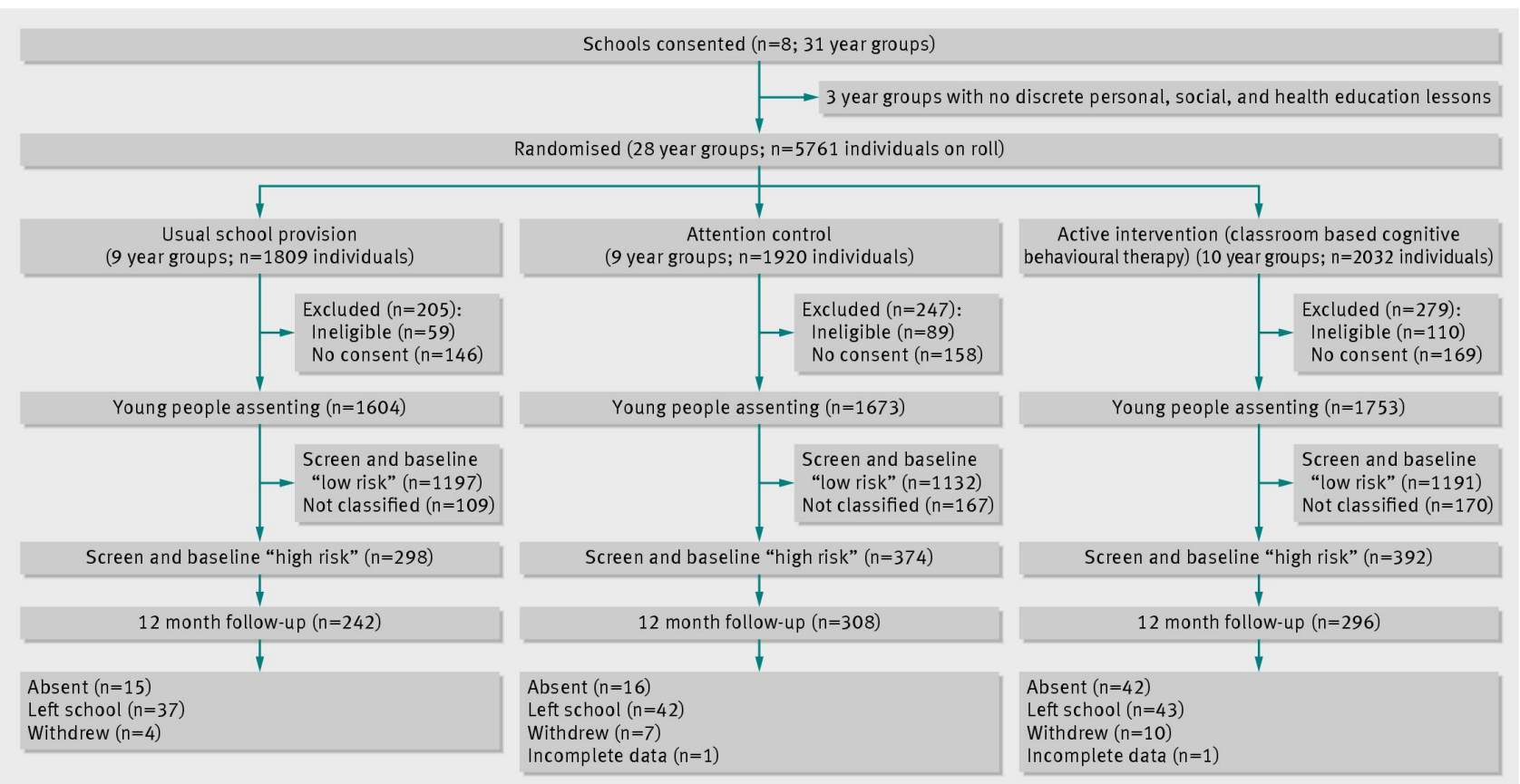

Flow of clusters and individual participants through study 